\title{
TRANSPARANSI PENILAIAN DENGAN METODE AUTHENTIC ASSESSMENT MELALUI APLIKASI WHATSAPP
}

\author{
Ismet* \\ Sekolah Dasar Negeri 4 Metro Timur Kota Metro Lampung \\ Jl. AH.Nasution No. 214 Kel. Yosodadi Kec. Metro Timur \\ *Corresponding Author : ismet.unila@gmail.com
}

\begin{abstract}
ABSTRAK
Abstrak: Masih rendahnya respon yang diberikan orang tua terhadap informasi yang disampaikan melalui grup whatsapp (WA) kelas dan tingginya keinginan orang tua siswa untuk mengetahui nilai yang diperoleh anak dalam setiap tes, mendorong guru untuk melakukan inovasi guna memecahkan permasalahan tersebut. Penelitian ini merupakan penelittain kualitatif yang bertujuan untuk menginformasikan proses penilaian melalui aplikasi whatsapp dengan metode authentic assessment. Subjek penelitian ini adalah siswa kelas III SD Negeri 4 Metro Timur dan Orang Tua siswa yang tergabung dalam group whatsapp kelas berjumlah 26 orang. Pengumpulan data dilakukan dengan cara melakukan pengamatan dengan lembar observasi dan wawancara langsung. Penyampaian informasi dilakukan oleh guru lewat WA dimulai dari proses penilaian, menyusun rubrik penilaian, melakukan penilaian baik tema maupun mata pelajaran hingga melaksanakan perbaikan nilai atau remedial. Dari hasil pengamatan diketahui bahwa orang tua siswa sangat antusias terhadap transparansi penilaian yang dilakukan oleh guru sebanyak $84 \%$ orang tua siswa melihat dan memberikan komentar, $12 \%$ yang melihat dan $4 \%$ yang tidak melihat dan tidak memberikan komentar. Orang tua menjadi paham proses penilaian hingga menunjukan hasil, bahkan sampai perbaikan nilai. Untuk itu transparansi penilaian akan terus dikembangkan tidak hanya fokus pada hasil ujian tetapi jugan terhadap proses kegiatan pembelajaran.
\end{abstract}

Kata Kunci : penilaian autentik, siswa SD, transparansi, whatsapp

\begin{abstract}
Abstract: The low response given by parents to the information conveyed through the whatsapp class group and the high desire of parents to find out the value of children in each test, encourages teachers to innovate to solve these problems. This research is a qualitative research that aims to inform the assessment process through the application of whatsapp with the authentic assessment method. The subjects of this study were students of class III SD Negeri 4 Metro Timur and parents of students who were members of the whatsapp class group of 26 people. Data collection is done by making observations with observation sheets and direct interviews. Submission of information is carried out by the teacher through WA starting from the assessment process, compiling an assessment rubric, evaluating both themes and subjects to carrying out improved grades or remedial. From the observations it is known that parents of students are very enthusiastic about the transparency of the assessment conducted by the teacher as much as $84 \%$ of students' parents see and comment, $12 \%$ see and $4 \%$ do not see and do not comment. Parents come to understand the assessment process to show results, even to the improvement of grades. For this reason, the transparency of assessment will continue to be developed, not only focusing on exam results but also on the learning process.
\end{abstract}

Key Word: authentic assessment, elementary student, whatsapp 


\section{PENDAHULUAN}

Perkembangan Teknologi Informasi dan Komunikasi (TIK) yang sangat pesat akhir-akhir ini membuat informasi cepat tersampaikan dari sumber informasi kepada pengguna informasi.Hal ini menuntut keterbukaan informasi dari segala bidang kehidupan sesuai dengan kebermanfaatannya masing-masing.

Dalam dunia pendidikan perkembangan TIK harus dimanfaatkan guna mendukung penyampaian dan pemahaman materi kepada peserta didik.Saat ini peserta didik rata-rata sudah melek informasi, informasi tersebut mereka peroleh dengan cepat melalui gawainya masing-masing.

Oleh sebab itu pendidik harus lebih mahir dalam menggunakan TIK untuk menghadapi peserta didik yang kritis dan dinamis akibat dari didikan dunia digital.

Untuk pendidikan setingkat SMP dan SMA penggunaan gawai yang tidak bertanggungjawab dapat menurukan kedisiplinan belajar siswa. Terjadi pengaruh yang signifikan bagi siswa SMP yang membawa gawai menggunakan aplikasi WA terhadap kedisiplinan belajar siswa [1]. Meskipun pada saat ini kita berada dalam era keterbukaan informasi namun penggunaan gawai di sekolah perlu di kontrol dengan peraturan yang ketat sehingga dampak negatif dari penggunaan gawai itu sendiri bisa kita cegah [2].

Jika siswa SD dipegangi gawai di sekolah kebermanfaatannya untuk hal yang positif belum terlalu besar. Anak SD masih senangsenangnya bermain, ketika difasilitasi gawai di sekolah dapat dipastikan mereka akan sibuk menggunakan gawainya untuk bermain game sendiri dibandingkan dengan berinteraksi bersama teman seusianya. Gawai sangat mempengaruhi perkembangan siswa SD terutama perkembangan dalam interaksi sosial dikarenakan lamanya durasi anak memainkan gawai [3].

Selain itu dalam menggunakan gawai anak-anak tidak memperhatikan pencayahaan dan posisi tubuh. Penelitian yang dilakukan oleh Maya dkk [4], diketahui bahwa posisi tubuh anak saat menggunakan gawai pada posisi duduk tegak sebanyak (54,4\%), responden menyatakan tidak pernah menggunakan gawai ketika cahaya redup sebanyak (51,5\%) dan responden menyatakan tidak menggunakan gawai ketika tidak ada cahaya sebanyak (50\%). Hal ini menunjukan masih besarnya presentase anak yang belum memperhatikan posisi tubuh dan pencahayaan pada saat menggunakan gawai yang akan mempengaruhi kesehatan mata mereka. Seperti yang diungkapkan oleh bahwa keseringan menatap layar gawai akan mengakibatkan penurunan ketajaman pengelihatan serta mata kering [5].

Terdapat dua pilihan, yang pertama anak dibiarkan menggunakan gawai di sekolah, yang kedua anak dilarang menggunakan gawai di sekolah. Dari hasil observasi di SD Negeri 4 Metro Timur dengan jumlah murid 560 orang lebih dari 80\% memiliki gawai dan 94\% pernah menggunakan gawai. Tetapi di SD Negeri 4 Metro Timur dilarang menggunakan gawai di sekolah.Tetapi masih saja ada siswa yang kedapatan membawa gawai ke sekolah walau pun akhirnya mendapatkan pembinaan khusus oleh sekolah.

Guna mengakomodir penggunaan gawai agar lebih bermanfaat maka sekolah memberi pengarahan kepada semua wali kelas untuk membuat grup kelas dengan memanfaatkan aplikasi WA. Grup ini akan dimanfaatkan oleh orang tua siswa dan siswa guna mendukung pembelajaran di sekolah. Khusus di grup WA wali murid kelas IIIA terdapat 26 anggota aktif dari jumlah 30 jumlah murid di kelas III.

Aplikasi WA memiliki peran penting dalam mendukung fungsi komunikasi organisasi yang meliputi fungsi produksi dan pengaturan, fungsi pembaharuan, fungsi pemeliharaan, fungsi tugas, fungsi perintah, dan fungsi relasional tetap dapat terkomunikasikan, dengan percepatan dan efisiensi dari fasilitas aplikasi Whatsappyang ditawarkan [6].

Selama ini grup WA yang dibentuk hanya digunakan untuk menginformasikan kegiatankegiatan rutin sekolah atau pun memberitahukan kepada guru bahwa anaknya ijin tidak masuk sekolah.Jika hanya dimanfaatkan sebagai penyampai informasi tersebut tidak menimbulkan banyak manfaat.Hal ini diketahui dari penelitian awal yang dilakukan ketika menyampaikan informasi rutin sekolah diperoleh data sebagai berikut. 
Tabel. 1 Respon orang tua terhadap Informasi di Whats App (WA)

\begin{tabular}{|l|l|l|}
\hline No. & \multicolumn{1}{|c|}{ Kriteria } & $\begin{array}{l}\text { Jumlah } \\
\text { Respon }\end{array}$ \\
\hline 1. & Dilihat & 15 \\
\hline 2. & Dikomentari & 6 \\
\hline 3. & $\begin{array}{l}\text { Tidak dilihat dan tidak } \\
\text { dikomentari }\end{array}$ & 5 \\
\hline
\end{tabular}

Dari tabel tersebut diketahui bahwa informasi rutin sekolah yang disampaikan melalui grup WA hanya dilihat saja, sedikit sekali respon berupa komentar.

Grup WA kelas dimanfaatkan guna penyampaian informasi penilaian yang dilakukan guru di sekolah dengan harapan terjadi interaksi yang aktif antara guru dan orang tua siswa guna mendukung keberhasilan belajar siswa di sekolah.Permasalahan yang timbul sebelumnya adalah ketika dilakukan laporan penilaian banyak orang tua siswa yang bertanya tentang nilai yang diperoleh anak.Pertanyaan tersebut timbul ketika orang tua meyakini anaknya mampu belajar dengan baik tetapi nilai yang diperoleh tidak sesuai harapan.Oleh sebab itu perlu dilakukan transparansi penilaian yang benar-benar mampu mengukur kemampuan anak.Penilaian harus mengacu pada Standar Penilaian yang salah satu tujuannya adalah pelaporan hasil penilaian peserta didik secara autentik (objektif, akuntabel, dan informatif [7]

\section{Referensi}

Authentik asessment is an effort to help teachers in elemntary classrooms implement perfomrmance-base learning and authetic assessment pratices thorughout the curriculum [8]. Penilaian autentik sangat membantu guru di dalam kelas guna mengiplementasikan tujuan dari kurikulum sehingga setiap perkembangan anak dapat terlihat dengan baik. Penilaian autentik juga mengajak para siswa dan orang tua wali untuk menselaraskan pengetahuan akademik dengan konteks dunia nyata agar lebih bermakna [9].
Penilaian autentik harus dilakukan guna terpenuhinya rasakeadilan dan akuntabilitas siswa dan orangtua siswa [10]. Ketika rasa keadilan dan akuntabilitas telah terpenuhi maka ketika pelaporan hasil belajar siswa tidak terjadi lagi protes atau pun sanggahan mengenai nilai baik dari orang tua atau pun siswa sendiri.

Salah satu media informasi yang sangat populer dan dapat digunakan guna transparansi penilaian adalah aplikasi whatsapp. Aplikasi whatsapp atau whatsapp messenger adalah aplikasi yang digunakan untuk mengirim pesan menggunakan data internet [11]. Aplikasi ini mirip dengan aplikasi messenger yang telah ada, hanya saja whatsapp menggunakan nomor ponsel sebagai identitas User.

Terdapat beberapa fitur yang terdapat pada aplikasi WA yaitu: 1) multiplatform yaitu dapat digunakan di beberapa jenis gawai seperti android, blackberry, windows phone dan symbian, oleh karena itu chatting bisa dilakukan dengan mudah, kapan saja dengan hampir semua jenis gawai; 2) multimedia yaitu mampu mengirim pesan berupa text, suara, gambar; video dan lokasi; 3) group chat, yaitu mendukung percakapan berbagi informasi dalam group; 4) tidak membutuhkan pin atau username; dan 5) tidak perlu log in atau log out [12].

Dari pendapat ahli di atas penulis menyimpulkan bahwa penilaian autentik yang menuntut guru untuk transparan dan akuntabel dalam menilai dapat memanfaatkan aplikasi group whatsapp dalam penyampaian informasi atau pun berdiskusi.

Rumusan masalah pada penelitian ini adalah "Efektifitas penggunaan gawai oleh guru dan orang tua siswa guna mendukung kegiatan pembelajaran di sekolah"

Penelitian ini bertujuan memberikan deskripsi efektifitas penggunaan gawai guna mendukung kegiatan belajar mengajar siswa. Lebih khusus gawai digunakan guna menginformasikan proses penilaian akhir semester melalui aplikasi whatsapp dengan metode authentic assessment.

\section{METODE}

Penelitian ini merupakan penelitian kualitatif evaluasi jenis studi kasus, Penelitian 
kualitatif evaluasi memiliki tujuan untuk melihat efektif tidaknya suatu program atau kebijakan [13]. Penelitian ini tidak sekedar untuk menjelaskan seperti apa objek yang diteliti tetapi juga untuk menjelaskan keberadaan dan bagaimana kasus tersebut dapat terjadi[14].

Dalam penelitian ini informasi diperoleh menggunakan metode pengamatan dan wawancara langsung dengan orang tua wali menggunakan instrumen pedoman observasi.

Penelitian dilakukan di kelas IIIa SD Negeri 4 Metro Timur dengan jumlah siswa 29 dan jumlah orang tua wali yang tergabung dalam grup whatsapp 26 orang.Penelitian dilaksanakan pada semester genap akhir tahun pelajaran 2018/2019 periode bulan Mei sampai Juni tahun 2019.

Analisis dan pengolahan data digunakan mengolah data guna memperoleh data yang dibutuhkan.Jenis data yang digunakan dalam penelitian ini adalah berupa data primer yang diperoleh secara mandiri dari hasil wawancara dan observasi serta data penelitian sebelumnya yang dianalisis selanjutnya disimpulkan.

\section{HASIL DAN PEMBAHASAN}

Kegiatan penelitian terdiri dari beberapa tahapan. Tahapan yang pertama adalah berkonsultasi dengan kepala sekolah, tahapan kedua melakukan penilaian terhadap hasil ulangan, tahapan ketiga adalah menganalisis hasil ulangan semester, tahapan keempat adalah mengumumkan hasil ulangan semester; tahapan terakhir adalah melakukan perbaikan nilai atau remedial.

Kegiatan pertama adalah melakukan konsultasi dengan kepala sekolah, hal ini dilakukan guna memperoleh arahan dan persetujuan tentang penelitian yang akan dilakukan penulis sebagai guru kelas III.

Setelah mendapat arahan dan persetujuan penulis mulai melakukan penilaian terhadap hasil ulangan semester.Sebagai guru kelas ada dua macam penilaian yang dilakukan penulis yaitu penilaian tematik dan penilaian mata pelajaran sesuai dengan kurikulum 2013.Penilian tematik dilakukan dengan menilai satu tema secara keseluruhan. Di kelas
3 semester 2 terdapat 4 tema yang dinilai yaitu tema 5, 6, 7 dan 8. Sedangkan untuk penilaian mata pelajaran dikelompokkan menjadi 4 mata pelajaran yaitu PPKn; Bahasa Indonesia; Matematika dan SBdP. Untuk dapat menilai baik secara tema atau pun mata pelajaran terlebih dahulu disusun rubrik penilaian. Soal yang dikerjakan siswa adalah soal yang dibuat dinas pendidikan kota, sehingga guru kelas harus membuat rubrik sendiri guna menentukan skor masing-masing tema dan mata pelajarannya.

Tabel 2. Rubrik Penilaian Tematik

\begin{tabular}{|c|c|c|c|c|c|c|c|c|}
\hline \multirow{3}{*}{ No } & \multirow{3}{*}{ Tema } & \multicolumn{6}{|c|}{ Soal } & \multirow[b]{3}{*}{ Total Skor } \\
\hline & & \multicolumn{2}{|c|}{ Pilihan Ganda } & \multicolumn{2}{|c|}{ Isian } & \multicolumn{2}{|c|}{ Essay } & \\
\hline & & $\mathrm{Jm} / \mathrm{h}$ & Bobot & Jmlh & Bobot & Jmlh & Bobot & \\
\hline \multirow[t]{5}{*}{1.} & Tema 5 & 25 & 1 & 8 & 2 & 8 & 3 & $=\frac{65}{65} \times 100=100$ \\
\hline & B.Indo & 8 & 1 & 2 & 2 & 2 & 3 & $=\frac{18}{-} \times 100=100$ \\
\hline & PKn & 4 & 1 & 2 & 2 & 2 & 3 & $=\frac{14}{14} \times 100=100$ \\
\hline & MTK & 5 & 1 & 2 & 2 & 2 & 3 & $=\frac{15}{-15} \times 100=100$ \\
\hline & SBdP & 8 & 1 & 2 & 2 & 2 & 3 & $=\frac{18}{-} \times 100=100$ \\
\hline \multirow[t]{5}{*}{2.} & Tema 6 & 20 & 1 & 8 & 2 & 4 & 3 & $=\frac{48}{-18} \times 100=100$ \\
\hline & B.Indo & 5 & 1 & 3 & 2 & 1 & 3 & $=\frac{14}{14} \times 100=100$ \\
\hline & PKn & 5 & 1 & 1 & 2 & 1 & 3 & $=\frac{10}{10} \times 100=100$ \\
\hline & MTK & 5 & 1 & 2 & 2 & 1 & 3 & $=\frac{12}{-12} \times 100=100$ \\
\hline & SBdP & 5 & 1 & 2 & 2 & 1 & 3 & $=\frac{12}{-12} \times 100=100$ \\
\hline \multirow[t]{5}{*}{3.} & Tema 7 & 20 & 1 & 8 & 2 & 4 & 3 & $=\frac{48}{-18} \times 100=100$ \\
\hline & B.Indo & 5 & 1 & 2 & 2 & 1 & 3 & $=\frac{12}{n} \times 100=100$ \\
\hline & PKn & 5 & 1 & 2 & 2 & 1 & 3 & $=\frac{12}{12} \times 100=100$ \\
\hline & MTK & 5 & 1 & 2 & 2 & 1 & 3 & $=\frac{12}{12} \times 100=100$ \\
\hline & SBdP & 5 & 1 & 2 & 2 & 1 & 3 & $=\frac{12}{-12} \times 100=100$ \\
\hline \multirow[t]{4}{*}{4.} & Tema 7 & 20 & 1 & 8 & 2 & 4 & 3 & $=\frac{12}{-12} \times 100=100$ \\
\hline & B.Indo & 5 & 1 & 6 & 2 & 4 & 3 & $=\frac{12}{12} \times 100=100$ \\
\hline & PKn & 5 & 1 & 2 & 2 & 4 & 3 & $=\frac{12}{12} \times 100=100$ \\
\hline & MTK & 5 & 1 & 4 & 2 & 4 & 3 & $=\frac{12}{n} \times 100=100$ \\
\hline
\end{tabular}

Setelah rubrik penilaian jadi maka guru melakukan koreksi terhadap hasil ulangan siswa.Koreksi dilanjutkan dengan analisis setiap butir soal secara bersamaan.

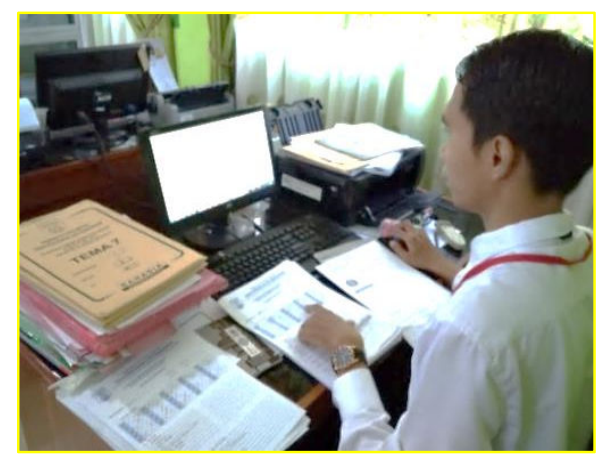

Gambar 1. Koreksi dan analisis soal

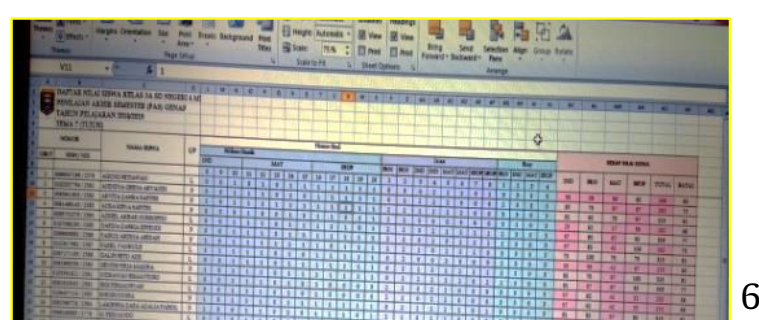


Gambar 2. Data Analisis Butir Soal di Komputer Setelah selesai koreksi guru mengumumkan hasil ulangan siswa baik dibagikan langsung LJK, menempel hasil ulangan di kelas dan mengumumkan hasil ulangan di grup Whatsapp kelas.

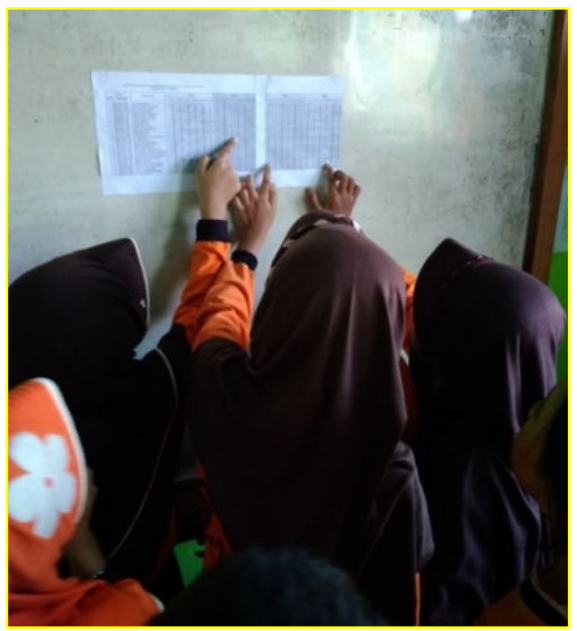

Gambar 3. Mengumumkan hasil ulangan di depan kelas

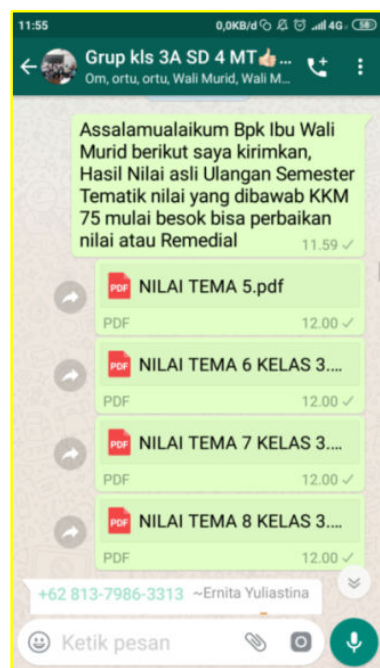

Gambar 4. Mengumumkan hasil ulangan lewat WA Group

Dari pengumuman yang dilakukan di group Whatsapp mendapatkan banyak sekali tanggapan positif dari orang tua/wali murid.Mereka sangat senang mengetahui transparansi yang dilakukan guru kelas III.Wali murid mengetahui hasil ujian semester anak secara tematik dan mata pelajaran.

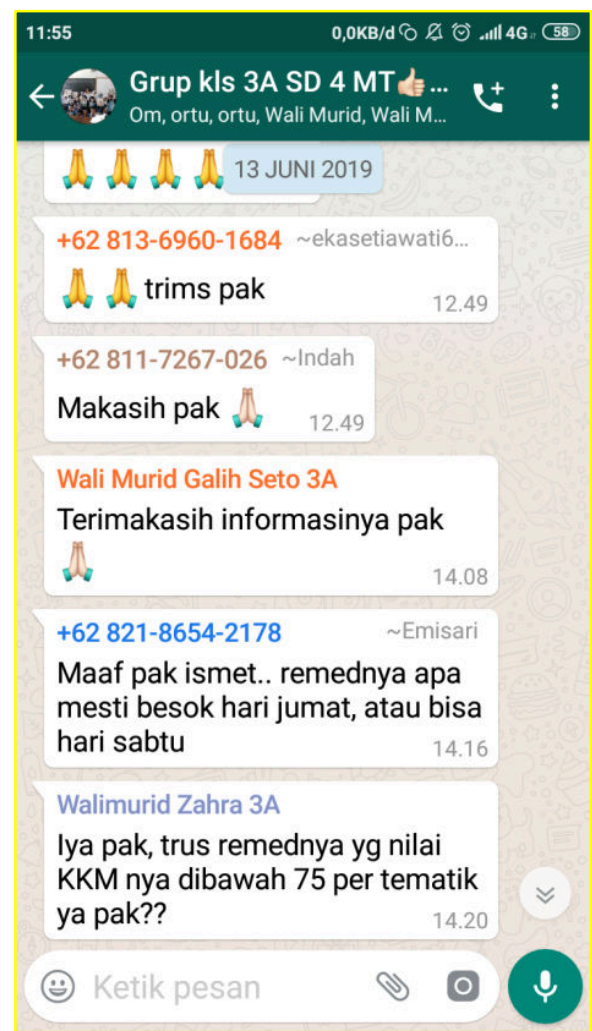

Gambar 5. Respon orang tua terhadap pengumuman hasil ujian di Group Wa

Dengan memanfaatkan aplikasi whatsapp guru dapat mengirimkan hasil ulangan baikberupa teks maupun file yang dapat dibuka dan dibaca oleh orang tua wali murid.

Setelah orang tua wali mengetahui nilai anaknya masing-masing selanjutnya guru kelas melaksanakan remedial untuk siswa yang menadapatkan nilai di bawah KKM.Dalam pengumuman di group WA juga telah diberi keterangan siapa saja yang remedial.

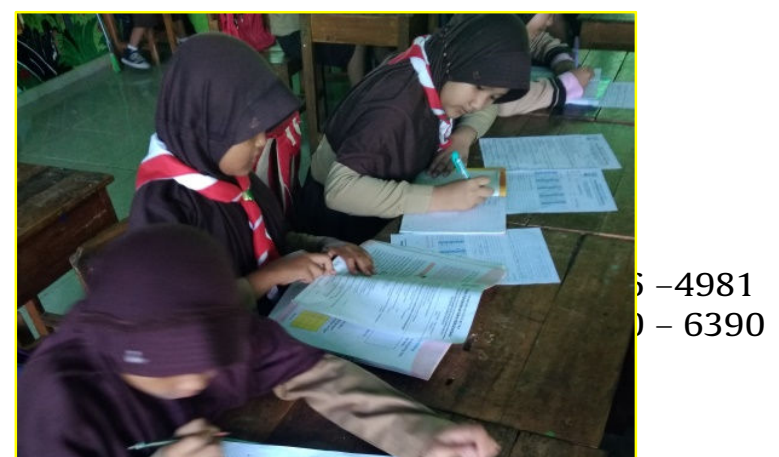




\section{Gambar 6. Siswa melaksanakan remedial}

Pada saat pelaksanaan remedial pun orang tua siswa aktif berkomunikasi dengan guru mengenai nilai anaknya.Banyak hal yang dikomunikasikan, dari soal remedial tematik atau mapel, waktu pelaksanaan remedial mapu pun nilai remedial itu sendiri.

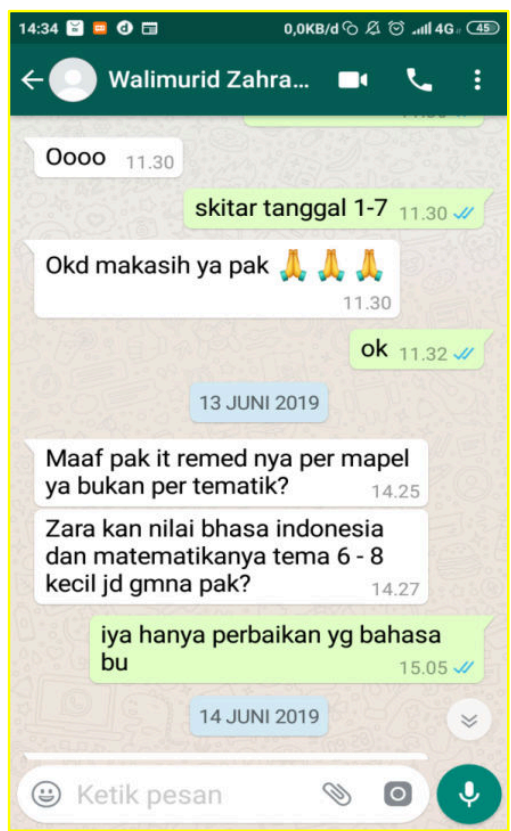

Gambar 7.Komunikasi dengan orang tua terhadap remedial

Dari beberapa langkah penilaian autentik yang telah dilaksanakan, masingmasing tahapan diobservasi menggunakan lembar observasi untuk mengetahui respon orang tua terhadap informasi penilaian autentik yang disampaikan melalui grup WA dengan hasil sebagai berikut.

Tabel 3. Respon Grup WA terhadap Pengumuman penilaian

\begin{tabular}{|c|l|c|c|c|}
\hline $\mathrm{N}$ & \multicolumn{1}{|c|}{ Tahapan } & $\begin{array}{c}\text { Kome } \\
\text { ntar }\end{array}$ & Dilihat & $\begin{array}{c}\text { Tidak } \\
\text { dilihat dan } \\
\text { dikomenta } \\
\mathrm{r}\end{array}$ \\
\hline 1 & $\begin{array}{l}\text { Penilaian } \\
\text { hasil Ujian }\end{array}$ & 21 & 4 & 2 \\
\hline 2 & Remedial & 20 & 5 & 1 \\
\hline 3 & $\begin{array}{l}\text { Analisis } \\
\text { Penilaian }\end{array}$ & 19 & 6 & 1 \\
\hline
\end{tabular}

Dari tabel di atas diketahui bahwa 95\% orang tua siswamemberikan respon terhadap hasil penilaian yang diumumkan. Hanya $4 \%$ saja yang tidak merespon sama sekali, hal ini dimungkinkan anggota grup tersebut tidak punya paketan data/wiffi untuk menerima pesan WA.

Dari proses penilaian autentik dan transparansi pengumuman menggunakan grup WA memberikan pemahaman kepada orang tua wali tentang proses penilaian yang dilakukan guru di sekolah. Dengan demikian orang tua siswa tidak berprasangka buruk kepada guru tentang penilaian. Nilai yang diperoleh siswa adalah nilai otentik benar-benar hasil dari proses penilaian yang dilakukan oleh guru.

\section{KESIMPULAN}

Guru harus membuka komunikasi yang seluas-luasnya kepada orang tua/wali murid dengan memanfaatkan teknologi yang ada agar terjalin kerja sama yang baik antara guru dan orang tua siswa dalam mendidik siswa tidak hanya disekolah tetapi juga di rumah.

Dengan adanya transparansi dalam penilian akan meminimalisir miss komunikasi antara orang tua dan guru pada saat menilai setiap tahapan perkembangan siswa baik perkembangan sikap, pengetahuan maupun keterampilan.

Koordinasi dan kerjasama antar seluruh warga sekolah dengan orang tua wali dan stakeholder agar lebih di tingkatkan untuk mengoptimalkan transparansi penilaian sehigga terjalin kerjasama antara guru dan orang tuas sis guna mengoptimalkan potensi setiap siswa. 


\section{DAFTAR PUSTAKA}

[1] Rahmansari Riskyta, (2012). Penggunaan Aplikasi Whatsapp dalam Komunikasi Organisasi Pegawai Dinas Lingkungan Hidup dan Kebersihan Sidoarjo. Sidoarjo Jawa Timur: Jurnal Ilmiah Manajemen Publik dan Kebijakan Sosial Vol. 1 No. 2. Universitas Dr. Sutomo. DOI: http://dx.doi.org/10.25139/jmnegara. v1i2.788 1

[2] Sihabudin Ahmad. (2013). Teknologi informasi Komunikasi dan Gaya Hidup Mahasiswa. Jurnal Teknodik. Jakarta: DOI: http://dx.doi.org/10.32550/teknodik. v0i0.77

[3] Witarsa Ramdhan, dkk. (2018). Pengaruh Penggunaan Gadget Terhadap Kemampuan Interaksi Sosial Siswa Sekolah Dasar:Jurnal Pedagogik Unisma Vol. VI, No. 1. http://jurnal.unismabekasi.ac.id/index.php /pedagogik/article/view/432

[4] Wishnu E.W. (2012). Aplikasi Chatting untuk Android. Jakarta:PT Alex Media Komputindo.

[5] Pertiwi Maya Syulfharita, dkk. (2018). Gambaran Perilaku Penggunaan Gawai dan Kesehatan MataPada Anak Usia 10-12 Tahun. Jurnal Keperawatan Muhamadiyah: Vol. 3 No. $1 . \quad$ DOI: http://dx.doi.org/10.30651/jkm.v3i1.1451

[6] Puspa Andriana Kirana, dkk. (2018). Pengaruh Penggunaan Gadget terhadap Penurunan Kualitas Penglihatan Siswa Sekolah Dasar:National and International Scientific Journal of Unisba. Global Medical and Health Communication: Vol. 6 No. 1 Tahun 2018.2 DOI: http://dx.doi.org/10.29313/gmhc.v6i1.2471

[7] Katherine Lunongo-Orlando. Authentic Assessment. Canada: Pembroke Publishers Limited

[8] J.R Raco (2017) Penelitian Kualitatif. Jakarta: Grasindo.

[9] Permendikbud No. 66 (2013) Standar Penilaian Pendidikan.

[10]Nursetyo Kunto Imbar, (2015). E-Portofolio Sebagai Penilaian Autentik Dalam Kurikulum 2013. Jurnal Teknodik.
Jakarta:DOI: http://dx.doi.org/10.32550/teknodik.v 19i2.161

[11]Elanine B. Johnson, (2007). Contextual Teaching and Learning: Menjadikan Kegiatan Belajar Mengajar Mengasikan dan Bermakna. Bandung. MLC.

[12]Pramana Agus Bayu dan Dewa Bagus.(2019). Penilaian Autentik. Bali: CVMedia Educations. 12

[13]Fitrah Muh. (2017. Penelitian Kualitatif, Tindakan Kelas dan Studi Kasus. Jakarta: CV Jejak.

[14]Suryadi Edi, dkk. (2018). Penggunaan Sosial Media Whatsapp dan Pengaruhnya Terhadap Disiplin Belajar Peserta Didik Pada Mata Pelajaran Pendidikan Agama Islam. Bogor: Jurnal Pendidikan Islam Vol.07, No. 1 STAI Al Hidayah. DOI: 10.30868/EI.V7I01.2

[15]Eliza.(2012). Kupas Tuntas Aplikasi Terbaik dan Populer Google Play.Jakarta: Elex Media Komputindo. 